\title{
Teores de cobalto e manganês em solos de Santa Catarina
}

\author{
Cobalt and manganese content in soils of Santa Catarina
}

\author{
Ilana Marin Suppi*, Mari Lucia Campos, David José Miquelluti \& Dreyce Kisholli Bueno
}

Universidade do Estado de Santa Catarina, Lages, SC, Brasil. *Autor para correspondência: ilanalgs@yahoo.com.br.

Submissão: 26/09/2017 / Aceite: 13/06/2018

\begin{abstract}
RESUMO
A concentração dos elementos no solo pode ter origem natural, devido a seu material de origem e grau de intemperismo, ou antropogênica. O estudo objetivou avaliar os teores naturais de cobalto e manganês em 56 perfis de solos representativos do estado de Santa Catarina (SC), coletados em ambientes sem interferência antrópica, buscando correlacionar os teores encontrados com atributos físicos e químicos dos solos. Foram utilizadas 107 amostras considerando os horizontes A e B. A extração dos elementos foi realizada segundo protocolo USEPA $3050 \mathrm{~B}$ em bloco digestor, e quantificado em espectrometria de emissão ótica com fonte de plasma acoplado indutivamente. Os teores de Co e Mn diferiram entre as classes de solos, mas não entre os horizontes A e B. Em geral, solos originários de rochas magmáticas básicas apresentaram maiores concentrações de ambos os elementos. Os Latossolos apresentaram menores teores de Co e Mn do que solos mais jovens, como Chernossolos, ambos os solos derivados de basalto. Os atributos relação silte/argila, soma de bases e saturação por bases se correlacionaram positivamente com os elementos estudados, além de ambos se correlacionarem fortemente entre si.
\end{abstract}

PALAVRAS-CHAVE: elementos-traço, concentração natural, solos representativos do estado de SC.

\begin{abstract}
The concentration of elements in the soil may be anthropogenic or of natural origin, according to their source material and weathering degree. This study aimed to evaluate natural contents of cobalt and manganese in 56 representative soil profiles in the state of Santa Catarina that were not subjected to anthropic contamination, and relate them with the physical and chemical attributes of their corresponding soils. A total of 107 samples were used considering horizons A and B. Soil samples were subjected to digestion process, using the USEPA 3050 B method, and determined by inductively coupled plasma optical emission spectrometry (ICP OES). Cobalt and manganese levels differed between their classes, but not their horizons. In general, soils originated from basic igneous rocks presented higher concentrations of both elements. Latosols originated from basalt presented lower levels of Co and Mn than younger soils such as Chernozems, which have the same source material. The attributes silt/clay ratio, base sum and base saturation were positively correlated with the elements studied, aside from showing a strong correlation between each other.
\end{abstract}

KEYWORDS: trace element, natural content, representative soils of Santa Catarina.

\section{INTRODUÇÃO}

A avaliação da qualidade de solo, quanto à presença de substâncias químicas e o grau de contaminação, deve ser efetuada com base em Valores Orientadores de Referência de Qualidade (VRQ), de Prevenção e de Investigação (FADIGAS et al. 2006, CONAMA 2009). Para gerar os VRQ se faz necessário um conjunto de classes de solo que garantam uma representatividade geomorfológica e pedológica e a determinação dos teores dos 20 elementos inorgânicos listados na resolução CONAMA 420/2009 (PRESTON et al. 2014). Esses elementos ocorrem naturalmente nos solos, porém seus teores podem ser aumentados pela atividade antrópica e assim representar risco aos seres vivos, principalmente à saúde humana (ATSDR 2015).

O estado de Santa Catarina está localizado na região sul do Brasil, possui 95,4 mil km², correspondente a $1,1 \%$ da área total brasileira. Entretanto, apresenta grande diversidade geomorfológica e climática, o que condicionou processos pedogenéticos específicos. Essas especificidades tornam inadequado o uso para solos catarinenses de valores de referência de qualidade obtidos para solos de 
outros estados brasileiros ou de outros países. Dos 20 elementos elencados na resolução CONAMA 420/2009, apenas, os teores naturais de sete elementos foram determinados para os solos de SC, sendo $\mathrm{Cr}, \mathrm{Cu}, \mathrm{Ni}, \mathrm{Pb}$ e Zn (HUGEN 2010, HUGEN et al. 2013), Ba e Cd (SOUZA 2015). Além desses elementos, estão também elencadas na mesma resolução o cobalto (Co) e o manganês $(\mathrm{Mn})$ e seus teores naturais e consequentemente seus valores de referência ainda não foram determinados para o estado de SC.

Elementos essenciais a vida, o Co componente da cobalamina, vitamina B12, e o Mn necessário para a formação óssea e da cartilagem, além de ser cofator de grande variedade de enzimas (ATSDR 2012), em excesso se tornam tóxicos aos animais. O excesso de Co causa aumento das células vermelhas do sangue, cardiomiopatia, hipotireoidismo, falha pancreática, hiperplasia da medula óssea, alguns tipos de câncer e deficiência de ferro e cobre (REIMANN \& CARITAT 1998, PLUMLEE \& ZIEGLER 2003). Enquanto que, exposição aguda ao $\mathrm{Mn}$ pode levar a distúrbios neurológicos, psicológicos, pneumonite e a ingestão em excesso pode resultar em cirrose hepática (PLUMLEE \& ZIEGLER 2003). É importante ressaltar que a população em geral é exposta ao $\mathrm{Mn}$ principalmente através da ingestão de alimentos, apesar de o $\mathrm{Mn}$ ser liberado antropicamente para $o$ ar em emissões industriais, queima de combustíveis fósseis e erupções vulcânicas (ATSDR 2012).

As principais fontes antropogênicas de cobalto são a aplicação de lodo contendo cobalto ou fertilizantes fosfatados, o descarte de resíduos e a deposição atmosférica de atividades como mineração, fundição, refino ou combustão (LISON 2007). Enquanto que, as fontes de Mn são o lodo de esgoto, a mineração e o processamento de minerais, as emissões provenientes da produção de ligas de aço e ferro, a combustão de combustíveis fósseis e em menor proporção os aditivos de combustível (HOWE et al. 2004).

O Co e $\mathrm{Mn}$ na crosta terrestre ocorrem em maiores teores nas rochas máficas e encontram-se associados ao $\mathrm{Fe}$ nos processos geoquímicos. Com isso, solos derivados de rochas máficas frequentemente apresentam teores de Co e Mn mais elevados (KABATA-PENDIAS \& MUKHERJEE 2007). No solo, Co e Mn participam de diversas reações incluindo precipitação, troca iônica, adsorção específica e a distribuição entre solução e fase sólida está fortemente relacionada com o pH (NORVELL 1988). Quanto maior o pH, menor é o teor de Co e Mn na solução do solo, pois há o aumento da adsorção específica e precipitação desses elementos (FORBES et al. 1976, ERNANI 2008). Em solos com baixa provisão de oxigênio, ocorrem reações de redução de $\mathrm{Mn}$, aumentando a sua concentração na solução do solo (ERNANI 2008), nesta condição o teor de Co na solução também aumenta (REIMANN \& CARITAT 1998). Portanto, em solos com baixo $\mathrm{pH}$ e/ou baixa disponibilidade de oxigênio, a mobilidade do Co e do $\mathrm{Mn}$ aumenta (ERNANI 2008).

O estudo objetivou avaliar os teores naturais de Co e Mn em 56 perfis de solos representativos do estado de SC e assim fornecer teores desses elementos para futura construção do VRQ.

\section{MATERIAL E MÉTODOS}

Foram avaliados os horizontes A e B de 56 perfis de solos do estado de SC, coletados, descritos e classificados (ALMEIDA et al. 2003, CORRÊA 2003, PAES SOBRINHO et al. 2009, ALMEIDA et al. 2009, BRINGHENTI et al. 2012, TESKE et al. 2013, COSTA et al. 2013, LUNARDI NETO \& ALMEIDA 2013, FERREIRA 2013) (Tabelas 1 e 2, Figura 1). Ao todo, foram utilizadas 107 amostras que compõem o banco de solos do Centro de Ciências Agroveterinárias (CAV) da Universidade do Estado de Santa Catarina (UDESC).

As amostras de solo foram moídas em gral de ágata e tamisadas em peneira de $145 \mathrm{~mm}$. Para a digestão utilizou-se o método United States Environmental Protection Agency (USEPA) 3050 B (USEPA 1996), em bloco digestor.

Todas as digestões foram feitas em duplicata e em cada bateria foi incluída uma amostra referência Standard Reference Materials (SRM) 2709 A, San Joaquin Soil, certificada pelo National Instituteof Standards and Technology (NIST) e uma amostra em branco para cálculo do Limite de Detecção Qualitativo do Método Analítico (LDQM). As taxas de recuperação da amostra referência SRM 2709A para Co e Mn obtidos após abertura pelo método 3050 B e quantificação em ICP OES são apresentados na Tabela 3.

O LDQM foi calculado segundo a equação LDQM $=F d \times(M \pm t \times s)$ (APHA 2012), onde Fd é o fator de diluição das amostras, $M$ é a média das provas em branco, $t$ é o valor t-Student para um intervalo de confiança de $99 \%$, em função do número de graus de liberdade de medições repetidas e $s$ é o desvio padrão das provas em branco. Os teores de Co e Mn foram determinados por espectrometria de emissão ótica com fonte de plasma acoplado indutivamente (ICP OES).

As análises estatísticas foram conduzidas utilizando-se um modelo linear hierárquico de efeitos fixos, em dois níveis. Consideraram-se os horizontes no primeiro nível e a classe de solos no segundo nível. As 
comparações entre classes de solos e entre horizontes dentro de cada classe foram testadas através dos testes $\mathrm{F}$ e Scott-Knott. Para atender as pressuposições teóricas dos testes, aplicou-se a transformação logarítmica das variáveis teor de cobalto e de manganês, conforme sugerido pela análise descritiva dos dados, no entanto, os resultados são apresentados na escala original. Todas as análises foram conduzidas usando-se o software R (R CORE TEAM 2016). Os teores de Co e Mn encontrados também foram submetidos a correlação de Pearson, utilizando-se as variáveis: teor de argila, relação silte/argila, soma de bases (SB) e valor de saturação de bases (V\%). Para todos os testes efetuados foi considerado o nível mínimo de significância de $5 \%$.

Tabela 1. Descrição dos 56 perfis de solo representativos de Santa Catarina, classes de solo, material de origem e município de coleta da amostra.

Table 1. Description of 56 soil profiles representative of Santa Catarina, soil classes, source material and city where sample collection was conducted.

\begin{tabular}{|c|c|c|c|}
\hline Material de Origem & Perfil & Classe de Solo & Município \\
\hline Andesito basalto & NBDIST & Nitossolo Bruno Distroférrico típico & Água Doce \\
\hline Arenito e siltito & AVADLL & Argissolo Vermelho-Amarelo Distrófico latossólico & Lauro Müller \\
\hline Arenito e siltito & AVADLLL & Argissolo Vermelho-Amarelo Distrófico latossólico & Lauro Müller \\
\hline Argilitos e siltitos & ABAAHNS & $\begin{array}{l}\text { Argissolo Bruno-Acinzentado Alítico húmico nitossólico } \\
\text { (sômbrico) }\end{array}$ & Alfredo Wagner \\
\hline Basalto & CHEAFTD & Chernossolo Argilúvico Férrico típico & Descanso \\
\hline Basalto & CHEAFTI & Chernossolo Argilúvico Férrico típico & Ipira \\
\hline Basalto & NLECHE & Neossolo Litólico Eutrófico chernossólico & Ipira \\
\hline Basalto & AAET & Argissolo Amarelo Eutrófico típico & Ipira \\
\hline Basalto & NVDT & Nitossolo Vermelho Distroférrico típico & Lages \\
\hline Basalto & NVAT & Nitossolo Vermelho Alítico típico & Lages \\
\hline Basalto & NVECHE & Nitossolo Vermelho Eutróférrico chernossólico & Descanso \\
\hline Basalto & CHAPETL & Cambissolo Háplico Eutrófico típico & Luzerna \\
\hline Basalto & CHAPETD & Cambissolo Háplico Eutrófico típico & Descanso \\
\hline Basalto & CHEHFT & Chernossolo Háplico Férrico típico & Descanso \\
\hline Basalto & NVETI & Nitossolo Vermelho Eutróférrico típico & Ipira \\
\hline Basalto & NVETL & Nitossolo Vermelho Eutrófico típico & Luzerna \\
\hline Basalto & CHUMDOS & Cambissolo Húmico Distrófico organossólico (sômbrico) & Bom Jardim da Serra \\
\hline Basalto & NBDT & Nitossolo Bruno Distrófico típico & Painel \\
\hline Basalto & CHUMDTB & Cambissolo Húmico Distrófico típico & Lages \\
\hline Basalto & NHAPDTB & Nitossolo Háplico Distrófico típico & Luzerna \\
\hline Basalto & LBVF & Latossolo Bruno Vermelho férrico & Campos Novos \\
\hline Basalto & LVF & Latossolo Vermelho Distroférrico húmico & Faxinal dos Guedes \\
\hline Basalto & LBRU & Latossolo Bruno & Curitibanos \\
\hline Basalto & LVDHLR & Latossolo Vermelho Distrófico retráticoúmbrico & Campos Novos \\
\hline Basalto & NBDR & Nitossolo Bruno Distrófico rúbrico & Lebon Regis \\
\hline Fonolito & CHAP & Cambissolo Háplico Alumínico úmbrico & Lages \\
\hline Fonolito & NEOSL & Neossolo Regolítico Húmico típico & Lages \\
\hline Fonolitoporfirítico & CHALUT & Cambissolo Háplico Alumínico típico & Lages \\
\hline Granito & NRET & Neossolo Regolítico Eutrófico típico & Sangão \\
\hline Granito & CHAPDT & Cambissolo Háplico Distrófico típico & Treze de Maio \\
\hline Granito & AVADT & Argissolo Vermelho-Amarelo Distrófico típico & Sangão \\
\hline Granito e Granulito & AVAS & Argissolo Amarelo Distrófico típico & Rancho Queimado \\
\hline Granulitomáfico & AVAATL & Argissolo Vermelho-Amarelo Alítico típico & Luiz Alves \\
\hline Granulitomáfico & AVAATB & Argissolo Vermelho-Amarelo Alumínico típico & Blumenau \\
\hline Horblendito & AADT & Argissolo Amarelo Distrófico típico & Pomerode \\
\hline Metaarenito & AVAATG & Argissolo Vermelho-Amarelo Alumínico típico & Gaspar \\
\hline Micaxisto & AAAT & Argissolo Amarelo Alítico típico & Botuverá \\
\hline Migmatito & AVADLA & Argissolo Vermelho-Amarelo Distrófico latossólico & Águas Mornas \\
\hline Migmatito & AVADLS & Argissolo Vermelho-Amarelo Distrófico latossólico & São Bonifácio \\
\hline Olivina melilitito & CHEHOT & Chernossolo Háplico Órtico típico & Palmeira \\
\hline Riodacito & CHALUU & Cambissolo Háplico Alumínico úmbrico & Lages \\
\hline Riodacito & CHUMDTR & Cambissolo Húmico Distrófico típico & Lages \\
\hline Riodacito & NHAPDTR & Nitossolo Háplico Distrófico típico & Luzerna \\
\hline Riodacito & $\mathrm{NLAH}$ & Neossolo Litólico Álico húmico & São Joaquim \\
\hline Riodacito & CHAPALI & Cambissolo Háplico Alítico típico & Lages \\
\hline Riodacito & NBDHLR & Nitossolo Bruno Distrófico húmico latossólico rúbrico & Ponte Serrada \\
\hline Riodacito & CHALUUU & Cambissolo Háplico Alumínico úmbrico & Lages \\
\hline Riodacito & CHAPALII & Cambissolo Háplico Alítico típico & Lages \\
\hline Riodacito & CHAPALIL & Cambissolo Háplico Alítico típico & Lages \\
\hline Sedimentos arenosos & NEOSI & Neossolo Quartzarênico Órtico típico & Imbituba \\
\hline Sedimentos arenosos & NEQUART & Neossolo Quartzarênico Órtico típico & Araranguá \\
\hline Sienitoporfiritico & CHAPAT & Cambissolo Húmico Alúminico típico & Lages \\
\hline Siltito & CHIST & Cambissolo hístico & Otacílio Costa \\
\hline Siltito e arenito & AVDS & Argissolo Vermelho Distrófico (sômbrico) & Içara \\
\hline Siltito e arenito & AVDSS & Argissolo Vermelho Distrófico (sômbrico) & Içara \\
\hline Siltito e arenito & AVDSI & Argissolo Vermelho Distrófico (sômbrico) & Içara \\
\hline
\end{tabular}


Tabela 2. Atributos físicos e químicos dos 56 perfis de solos estudados.

Table 2. Physical and chemical attributes of the 56 soil profiles studied.

\begin{tabular}{|c|c|c|c|c|c|c|}
\hline Perfil & Relação Silte/Argila* & $\begin{array}{l}\text { Argila* } \\
\left(\mathrm{g} \mathrm{kg}^{-1}\right)\end{array}$ & $\begin{array}{l}\text { Areia* } \\
\left(\mathrm{g} \mathrm{kg}^{-1}\right)\end{array}$ & $\mathrm{pH}$ (água)* & $\begin{array}{l}\mathrm{SB}^{\star} \\
\left(\mathrm{cmolc} \mathrm{kg}^{-1}\right)\end{array}$ & $\begin{array}{l}\mathrm{V}^{*} \\
(\%)\end{array}$ \\
\hline$\overline{\text { NBDIST }}$ & 0,48 & 575 & 151 & 5,16 & 2,26 & 20,9 \\
\hline AVADLL & 0,28 & 399 & 490 & 4,72 & 1,10 & 25,1 \\
\hline AVADLLL & 0,28 & 399 & 490 & 4,72 & 1,10 & 25,1 \\
\hline ABAAHNS & 0,60 & 446 & 286 & 4,60 & 0,75 & 4,5 \\
\hline NBDT & 0,35 & 664 & 104 & 5,18 & 1,24 & 10,6 \\
\hline NBDR & 0,36 & 715 & 30 & 4,89 & 2,12 & 12,3 \\
\hline LVDHLR & 0,22 & 807 & 13 & 4,75 & 0,94 & 7,3 \\
\hline CHUMDTB & 0,37 & 610 & 165 & 5,08 & 1,06 & 13,2 \\
\hline CHUMDOS & 0,66 & 406 & 327 & 5,10 & 0,75 & 6,3 \\
\hline NVDT & 0,33 & 640 & 148 & 4,60 & 5,65 & 31,6 \\
\hline NVAT & 0,16 & 757 & 122 & 4,90 & 6,40 & 40,2 \\
\hline LVF & 0,36 & 682 & 73 & 4,80 & 4,10 & 23,3 \\
\hline LBVF & 0,22 & 803 & 17 & 4,75 & 0,90 & 7,0 \\
\hline LBRU & 0,21 & 803 & 28 & 4,80 & 0,55 & 5,4 \\
\hline CHAPETD & 0,39 & 561 & 221 & 5,03 & 8,30 & 65,1 \\
\hline CHEAFTD & 0,88 & 416 & 219 & 5,74 & 27,16 & 91,8 \\
\hline CHEHFT & 1,00 & 345 & 310 & 6,21 & 27,82 & 92,7 \\
\hline NVECHE & 0,30 & 674 & 123 & 5,48 & 12,18 & 82,5 \\
\hline NVETI & 0,96 & 455 & 110 & 5,75 & 12,84 & 76,2 \\
\hline CHEAFTI & 1,22 & 347 & 228 & 5,94 & 21,15 & 87,3 \\
\hline AAET & 0,66 & 468 & 225 & 6,43 & 18,37 & 91,9 \\
\hline NLECHE & 2,07 & 280 & 140 & 5,50 & 19,15 & 82,6 \\
\hline NHAPDTB & 0,48 & 637 & 58 & 4,74 & 4,40 & 31,7 \\
\hline CHAPETL & 0,47 & 440 & 355 & 5,05 & 5,64 & 41,0 \\
\hline NVETL & 0,88 & 455 & 145 & 5,45 & 6,14 & 63,0 \\
\hline NEOSL & 0,25 & 560 & 300 & 4,77 & 4,31 & 28,2 \\
\hline CHAP & 0,50 & 530 & 205 & 4,63 & 1,92 & 13,8 \\
\hline CHALUT & 0,43 & 560 & 200 & 4,63 & 1,09 & 11,0 \\
\hline NRET & 1,34 & 160 & 625 & 4,08 & 1,44 & 58,3 \\
\hline CHAPDT & 0,33 & 422 & 438 & 4,71 & 0,49 & 11,0 \\
\hline AVADT & 0,42 & 418 & 408 & 4,52 & 0,37 & 12,8 \\
\hline AVAS & 0,93 & 410 & 210 & 4,50 & 0,65 & 8,3 \\
\hline AVAATL & 0,43 & 471 & 325 & 4,91 & 3,94 & 28,0 \\
\hline AVAATB & 0,37 & 412 & 437 & 4,29 & 3,56 & 26,5 \\
\hline AADT & 0,57 & 322 & 493 & 5,65 & 2,51 & 28,7 \\
\hline AVAATG & 0,19 & 510 & 393 & 4,04 & 2,21 & 18,9 \\
\hline AAAT & 0,51 & 389 & 412 & 4,74 & 5,38 & 36,4 \\
\hline AVADLA & 0,35 & 487 & 344 & 4,61 & 0,41 & 10,7 \\
\hline AVADLS & 0,50 & 451 & 325 & 4,79 & 1,06 & 17,1 \\
\hline CHEHOT & 1,65 & 240 & 365 & 6,37 & 8,06 & 62,5 \\
\hline NBDHLR & 0,31 & 707 & 74 & 4,85 & 3,95 & 26,3 \\
\hline CHALUU & 0,43 & 600 & 145 & 4,84 & 4,68 & 26,9 \\
\hline CHAPALI & 0,30 & 688 & 106 & 4,14 & 1,00 & 6,2 \\
\hline CHALUUU & 0,42 & 645 & 82 & 3,95 & 1,50 & 6,7 \\
\hline CHUMDTR & 0,37 & 643 & 118 & 3,95 & 0,95 & 9,1 \\
\hline CHAPALII & 0,43 & 640 & 85 & 4,45 & 1,65 & 5,3 \\
\hline CHAPALIL & 0,48 & 607 & 104 & 4,48 & 1,55 & 10,4 \\
\hline $\mathrm{NLAH}$ & 0,69 & 475 & 195 & 4,25 & 1,90 & 6,0 \\
\hline NHAPDTR & 0,28 & 731 & 64 & 4,75 & 1,60 & 17,1 \\
\hline NEOSI & 0,67 & 42 & 930 & 6,21 & - & - \\
\hline NEQUART & 0,97 & 33 & 935 & 4,35 & - & - \\
\hline CHAPAT & 0,48 & 575 & 150 & 4,40 & 1,89 & 12,4 \\
\hline CHIST & 0,58 & 467 & 261 & 4,27 & 0,30 & 1,6 \\
\hline AVDS & 0,30 & 402 & 478 & 4,88 & 1,32 & 27,6 \\
\hline AVDSS & 0,30 & 402 & 478 & 4,88 & 1,32 & 27,6 \\
\hline AVDSI & 0,26 & 330 & 585 & 4,65 & 1,40 & 29,3 \\
\hline
\end{tabular}

${ }^{*}$ Os atributos físicos e químicos apresentados nesta tabela foram obtidos por ALMEIDA et al. (2003), CORRÉA (2003), PAES SOBRINHO et al. (2009), ALMEIDA et al. (2009), BRINGHENTI et al. (2012), TESKE et al. (2013), COSTA et al. (2013), LUNARDI NETO \& ALMEIDA (2013) e FERREIRA (2013).

Tabela 3. Teores recuperados e certificados de cobalto e manganês para amostra referência SRM 2709 e LDQM.

Table 3. Recovered contents and certificates of cobalt and manganese in reference sample SRM 2709 and LQDM.

\begin{tabular}{|c|c|c|c|c|}
\hline Elemento & Teor recuperado ${ }^{(1)}$ & Teor Certificado ${ }^{(2)}$ & Recuperação(3) & LDQM \\
\hline & --------- $\mathrm{mg} \mathrm{kg}^{-1}$ & --------- & $\%$ & $\mathrm{mg} \mathrm{kg}^{-1}$ \\
\hline Co & 8,29 & $12,8 \pm 0,2$ & 65 & 1,83 \\
\hline $\mathrm{Mn}$ & 409,4 & $529 \pm 18$ & 77 & 1,94 \\
\hline
\end{tabular}




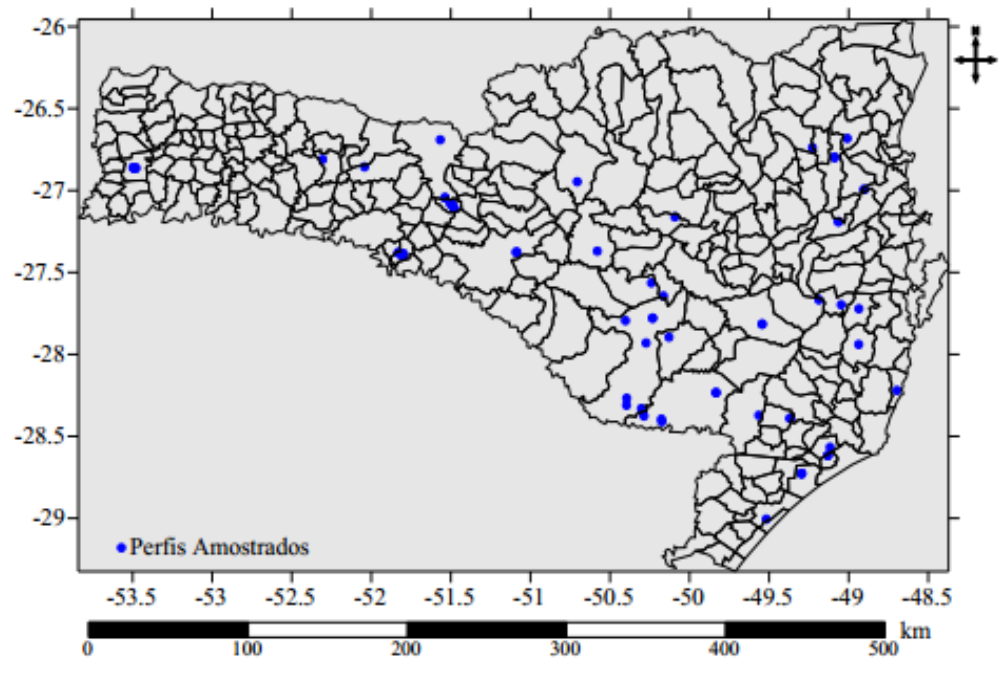

Fonte: SOUZA 2015

Figura 1. Mapa com a localização dos 56 perfis amostrados no estado de SC. Figure 1. Map with location of the 56 profiles sampled in the state of SC.

\section{RESULTADOS E DISCUSSÃO}

Houve diferença estatística significativa para teores de Co e Mn entre as classes de solo, porém, não foi observada diferença significativa entre horizontes e nem interação entre classe de solo e horizonte. Para os dois elementos estudados foram formados 3 grupos ( $A, B, C)$, onde solos de mesmo agrupamento não tiveram seus teores médios diferentes estatisticamente.

Os solos do grupo A (Tabela 4) foram os que apresentaram maiores teores de Co. Estes solos são derivados dos materiais basalto, andesito basalto e olivina melitito. Isso se deve as altas concentrações de Co em rochas magmáticas básicas, ou seja, este elemento geralmente é encontrado em maior quantidade nos solos desenvolvidos a partir destas do que em solos formados sobre rochas magmáticas ácidas, uma vez que o ciclo geoquímico de Co é bastante semelhante ao do Fe. Além disso os óxidos e hidróxidos de Fe presentes no solo adsorvem especificamente o Co, sendo que a mobilidade desse aumenta quando os óxidos e hidróxidos de Fe estão ausentes (BARCELOUX 1999, KABATA-PENDIAS \& MUKHERJEE 2007).

Maiores teores de Co para solos derivados de basalto também foram encontrados em Minas Gerais (CAIRES 2009) e em Pernambuco (BIONDI et al. 2011). Ainda dentro do grupo A, pode-se observar que os maiores teores de Co observados foram para Chernossolos Argilúvicos Férricos típicos $\left(135,7 \mathrm{mg} \mathrm{kg}^{-1} \mathrm{e}\right.$ $99,6 \mathrm{mg} \mathrm{kg}^{-1}$ ) e Neossolo Litólico Eutrófico chernossólico (93,9 mg kg ${ }^{-1}$ ), ou seja, solos mais jovens, menos intemperizados, e que tendem a manter maior relação com o material de origem e consequentemente apresentar maiores teores naturais de Co (XAVIER 2013).

O grupo B apresenta em sua maioria solos derivados de basalto, riodacito e horblendito, sendo os solos derivados de basalto os que apresentaram os maiores valores de Co dentro do grupo. Também no grupo $\mathrm{C}$ os solos com maiores de teores de Co derivam de basalto e riodacito. Dentro deste grupo encontram-se os Latossolos derivados de basalto com teores de Co variando entre 15,69 $\mathrm{mg} \mathrm{kg}^{-1}$ e 9,92 mg $\mathrm{kg}^{-1}$.

Os menores teores de Co foram encontrados em solos oriundos de sedimentos arenosos $(4,49 \mathrm{mg}$ $\mathrm{kg}^{-1}$ e 4,82 $\mathrm{mg} \mathrm{kg}^{-1}$ ), já que são materiais com predominância da fração areia com menor capacidade de adsorção de elementos-traço (HE et al. 2005, COSTA 2013) e por consequência mais pobres em Co.

Os teores médios de Co verificados nos Argissolos catarinenses $\left(8,02 \mathrm{mg} \mathrm{kg}^{-1}\right)$ e para Cambissolos $\left(13,06 \mathrm{mg} \mathrm{kg}^{-1}\right)$ foram semelhantes aos encontrados por CAIRES (2009) para solos de Minas Gerais (9,44 e $14,85 \mathrm{mg} \mathrm{kg}^{-1}$, respectivamente). Por outro lado, os teores de Co encontradas neste trabalho foram superiores às encontradas para solos naturais de Pernambuco (BIONDI et al. 2011), apesar de os autores terem associado maiores valores para solos que continham basalto em sua composição ou solos menos intemperizados. Os teores encontrados neste estudo também diferiram dos encontrados para solos naturais do Rio Grande do Norte (COSTA 2013), Mato Grosso e Rondônia (SANTOS \& ALLEONI 2013).

Os teores de Mn encontrados para os diferentes solos são apresentados na Tabela 5. Os grupos $\mathrm{A} \mathrm{e}$ B contém os solos originários de basalto, dois Chernossolos Argilúvico Férrico típico $\left(3871,58 \mathrm{mg} \mathrm{kg}^{-1} \mathrm{e}\right.$ $3715,80 \mathrm{mg} \mathrm{kg}^{-1}$ ) e o menor no Latossolo $\left(158,00 \mathrm{mg} \mathrm{kg}^{-1}\right)$. Para um mesmo material de origem, solos mais jovens apresentaram maiores teores de $\mathrm{Mn}$ que solos mais intemperizados, pois ambientes de intemperismo menos intenso possibilitam maior concentração e manutenção de $\mathrm{Mn}$ no sistema solo 
(BIONDI 2011). Além disso, os Chernossolos apresentaram maior valor de pH e por isso há maior adsorção específica e precipitação de Mn e consequentemente menor concentração na solução do solo (ERNANI 2008) e, portanto, menor lixiviação desse metal. As diferenças entre pH e grau de intemperismo dos solos podem ser responsáveis pelas grandes variações nos teores de Mn entre solos oriundos de basalto.

Tabela 4. Teores médios de Co para os 56 perfis de solo extraídos pelo método USEPA 3050 B, quantificados em ICP OES, seu material de origem e agrupamento estatístico.

Table 4. Mean Co contents for the 56 soil profiles extracted by the USEPA 3050 B method, quantified in ICPOES, their source material and statistical grouping.

\begin{tabular}{|c|c|c|c|}
\hline Grupo & Material de Origem & Perfil & $\begin{array}{l}\text { Teores de Co } \\
\left(\mathrm{mg} \mathrm{kg}^{-1}\right)\end{array}$ \\
\hline \multirow{13}{*}{ A } & Basalto & CHEAFTI & $135,7 \mathrm{a}^{(1)}$ \\
\hline & Basalto & CHEAFTD & $99,6 \mathrm{a}$ \\
\hline & Basalto & NLECHE & $93,9 \mathrm{a}$ \\
\hline & Basalto & AAET & $85,3 \mathrm{a}$ \\
\hline & Basalto & NVDT & $83,4 \mathrm{a}$ \\
\hline & Basalto & NVAT & $82,0 \mathrm{a}$ \\
\hline & Basalto & NVETI & $75,9 a$ \\
\hline & Olivina melilitito & CHEHOT & $71,7 \mathrm{a}$ \\
\hline & Basalto & CHAPETD & $69,1 \mathrm{a}$ \\
\hline & Andesito basalto & NBDIST & $64,7 \mathrm{a}$ \\
\hline & Basalto & NVECHE & $64,2 \mathrm{a}$ \\
\hline & Basalto & CHEHFT & $57,7 \mathrm{a}$ \\
\hline & Basalto & CHAPETL & $57,0 \mathrm{a}$ \\
\hline \multirow{9}{*}{ B } & Basalto & NVETL & $34,5 \mathrm{~b}$ \\
\hline & Basalto & CHUMDOS & $29,7 b$ \\
\hline & Basalto & NBDT & $29,4 b$ \\
\hline & Basalto & CHUMDTB & $29,2 b$ \\
\hline & Basalto & NBDR & $27,7 \mathrm{~b}$ \\
\hline & Riodacito & CHALUU & $24,6 \mathrm{~b}$ \\
\hline & Basalto & NHAPDTB & $23,9 \mathrm{~b}$ \\
\hline & Riodacito & CHAPALII & $23,3 \mathrm{~b}$ \\
\hline & Horblendito & AADT & $23,0 \mathrm{~b}$ \\
\hline \multirow{34}{*}{ C } & Riodacito & NBDHLR & $18,8 \mathrm{c}$ \\
\hline & Basalto & LBVF & $15,6 \mathrm{c}$ \\
\hline & Riodacito & CHAPALIL & $15,2 \mathrm{c}$ \\
\hline & Riodacito & NHAPDTR & $14,2 \mathrm{c}$ \\
\hline & Riodacito & NLAH & $13,5 \mathrm{c}$ \\
\hline & Basalto & LVF & $13,2 \mathrm{c}$ \\
\hline & Riodacito & CHAPALI & $13,0 \mathrm{c}$ \\
\hline & Riodacito & CHUMDTR & $12,9 \mathrm{c}$ \\
\hline & Granulitomáfico & AVAATL & $12,2 \mathrm{c}$ \\
\hline & Basalto & LBRU & $11,7 \mathrm{c}$ \\
\hline & Arenito e siltito & AVADLLL & $11,5 \mathrm{c}$ \\
\hline & Migmatito & AVADLS & $10,7 \mathrm{c}$ \\
\hline & Basalto & LVDHLR & $9,9 \mathrm{c}$ \\
\hline & Fonolito & NEOSL & $9,3 \mathrm{c}$ \\
\hline & Granito & NRET & $9,0 \mathrm{c}$ \\
\hline & Argilitos e siltitos & ABAAHNS & $9,0 \mathrm{c}$ \\
\hline & Sienitoporfiritico & CHAPAT & $8,8 \mathrm{c}$ \\
\hline & Riodacito & CHALUUU & $8,7 \mathrm{c}$ \\
\hline & Fonolitoporfirítico & CHALUT & $8,5 \mathrm{c}$ \\
\hline & Siltito e arenito & AVDSI & $8,3 \mathrm{c}$ \\
\hline & Siltito e arenito & AVDSS & $8,2 \mathrm{c}$ \\
\hline & Granito & CHAPDT & $7,7 \mathrm{c}$ \\
\hline & Arenito e siltito & AVADLL & $7,7 \mathrm{c}$ \\
\hline & Siltito & CHIST & $7,7 \mathrm{c}$ \\
\hline & Micaxisto & AAAT & $7,7 \mathrm{c}$ \\
\hline & Migmatito & AVADLA & $7,5 \mathrm{c}$ \\
\hline & Granito & AVADT & $7,5 \mathrm{c}$ \\
\hline & Siltito e arenito & AVDS & $7,3 \mathrm{c}$ \\
\hline & Granulitomáfico & AVAATB & $6,8 \mathrm{c}$ \\
\hline & Fonolito & $\mathrm{CHAP}$ & $6,6 \mathrm{c}$ \\
\hline & Metaarenito & AVAATG & $6,4 \mathrm{c}$ \\
\hline & Granito e granulito & AVAS & $4,9 \mathrm{c}$ \\
\hline & Sedimentos arenosos & NEOSI & $4,5 \mathrm{c}$ \\
\hline & Sedimentos arenosos & NEQUART & $4,8 \mathrm{c}$ \\
\hline
\end{tabular}

${ }^{(1)}$ Médias seguidas de mesma letra na coluna não diferem entre si pelo teste Scott-Knott $(p<0,05)$. 
Tabela 5. Teores médios de Mn para os 56 perfis de solo extraídos pelo método USEPA 3050 B, quantificados em ICP OES, seu material de origem e agrupamento estatístico.

Table 5. Mean Mn contents for the 56 soil profiles extracted by the USEPA 3050 B method, quantified in ICP OES, their source material and statistical grouping.

\begin{tabular}{|c|c|c|c|}
\hline Grupo & Material de Origem & Perfil & $\begin{array}{l}\text { Teores de } \mathrm{Mn} \\
\left(\mathrm{mg} \mathrm{kg}^{-1}\right)\end{array}$ \\
\hline \multirow{21}{*}{$A$} & Basalto & CHEAFTI & $3871,5 \mathrm{a}^{(1)}$ \\
\hline & Basalto & CHEAFTD & $3715,8 \mathrm{a}$ \\
\hline & Basalto & AAET & $2885,1 \mathrm{a}$ \\
\hline & Fonolitoporfirítico & CHALUT & $2522,6 \mathrm{a}$ \\
\hline & Basalto & NVDT & $2519,8 \mathrm{a}$ \\
\hline & Basalto & NLECHE & $2290,8 \mathrm{a}$ \\
\hline & Basalto & NVAT & $2072,1 \mathrm{a}$ \\
\hline & Basalto & NVETI & $1930,1 \mathrm{a}$ \\
\hline & Olivina melitito & CHEHOT & $1735,8 \mathrm{a}$ \\
\hline & Basalto & NVECHE & $1700,9 a$ \\
\hline & Basalto & CHAPETL & $1551,2 \mathrm{a}$ \\
\hline & Basalto & CHEHFT & $1544,4 \mathrm{a}$ \\
\hline & Andesito basalto & NBDIST & $1345,4 \mathrm{a}$ \\
\hline & Horblendito & AADT & $1169,6 \mathrm{a}$ \\
\hline & Basalto & CHAPETD & $1114,3 \mathrm{a}$ \\
\hline & Fonolito & NEOSL & $1043,4 \mathrm{a}$ \\
\hline & Arenito e siltito & AVADLL & $933,1 \mathrm{a}$ \\
\hline & Basalto & NVETL & $798,5 \mathrm{a}$ \\
\hline & Fonolito & CHAP & $754,1 \mathrm{a}$ \\
\hline & Basalto & NHAPDTB & 624,3 a \\
\hline & Riodacito & CHAPALII & 599,6 a \\
\hline \multirow{21}{*}{ B } & Granito & NRET & $492,7 b$ \\
\hline & Arenito e siltito & AVADLLL & $491,5 b$ \\
\hline & Sienitoporfirítico & CHAPAT & $449,3 \mathrm{~b}$ \\
\hline & Riodacito & CHALUU & $412,9 b$ \\
\hline & Basalto & CHUMDTB & $378,9 \mathrm{~b}$ \\
\hline & Riodacito & CHAPALIL & $307,3 \mathrm{~b}$ \\
\hline & Basalto & NBDT & $300,8 \mathrm{~b}$ \\
\hline & Basalto & LVDHLR & $287,2 \mathrm{~b}$ \\
\hline & Basalto & NBDR & $274,0 \mathrm{~b}$ \\
\hline & Riodacito & $\mathrm{NLAH}$ & $258,5 b$ \\
\hline & Basalto & CHUMDOS & $257,9 \mathrm{~b}$ \\
\hline & Basalto & LBVF & $256,4 \mathrm{~b}$ \\
\hline & Basalto & LVF & $209,1 \mathrm{~b}$ \\
\hline & Granito & AVADT & $207,5 b$ \\
\hline & Riodacito & NHAPDTR & $204,1 b$ \\
\hline & Riodacito & CHALUUU & $193,5 b$ \\
\hline & Riodacito & CHUMDTR & $192,0 \mathrm{~b}$ \\
\hline & Riodacito & NBDHLR & $179,0 \mathrm{~b}$ \\
\hline & Basalto & LBRU & $158,0 \mathrm{~b}$ \\
\hline & Granito & CHAPDT & $135,6 b$ \\
\hline & Riodacito & CHAPALI & $101,9 \mathrm{~b}$ \\
\hline \multirow{14}{*}{ C } & Siltito e arenito & AVDSS & $84,8 \mathrm{c}$ \\
\hline & Siltito e arenito & AVDS & $71,7 \mathrm{c}$ \\
\hline & Migmatito & AVADLS & $74,8 \mathrm{c}$ \\
\hline & Siltito & CHIST & $59,1 \mathrm{c}$ \\
\hline & Sedimentos arenosos & NEQUART & $57,7 \mathrm{c}$ \\
\hline & Siltito e arenito & AVDSI & $56,4 \mathrm{c}$ \\
\hline & Micaxisto & AAAT & $55,6 \mathrm{c}$ \\
\hline & Granulitomáfico & AVAATL & $44,7 \mathrm{c}$ \\
\hline & Argilitos e siltitos & ABAAHNS & $41,1 \mathrm{c}$ \\
\hline & Migmatito & AVADLA & $39,9 \mathrm{c}$ \\
\hline & Sedimentos arenosos & NEOSI & $39,4 \mathrm{c}$ \\
\hline & Granulitomáfico & AVAATB & $25,2 \mathrm{c}$ \\
\hline & Granito e granulito & AVAS & $22,6 \mathrm{c}$ \\
\hline & Metaarenito & AVAATG & $17,2 \mathrm{c}$ \\
\hline
\end{tabular}

\footnotetext{
${ }^{(1)}$ Médias seguidas de mesma letra não diferem entre sipelo teste Scott-Knott $(p<0,05)$
}

Altas concentrações de $\mathrm{Mn}$ também foram observadas nos solos provenientes de andesito basalto e olivina melitito. Assim como o Co, o teor de Mn é alto em rochas máficas, e desta forma, os teores naturais deste elemento em solos originados destas rochas, na maioria das vezes são altos, pois o Mn é um membro da família de ferro e ambos estão fortemente associados em processos geoquímicos, assim, o ciclo Mn 
segue o ciclo do Fe em vários ambientes geoquímicos (KABATA-PENDIAS \& MUKHERJEE 2007). Maiores valores de Mn para solos derivados de basalto também foram encontrados por CAIRES (2009) e BIONDI et. al. (2011). Estes autores observaram teores superiores de $\mathrm{Mn}$ em solos procedentes de rochas máficas.

Os solos formados a partir de riodacito, uma rocha intermediária, ficaram quase todos classificados no grupo B. Já os solos originários de sedimentos arenosos apresentaram baixos teores de $\mathrm{Mn}$ e encontram-se no grupo C. Isto ocorre porque a maior parte do teor concentração de $\mathrm{Mn}$ nos solos deriva de seu material de origem (LI et al. 2001).

As concentrações médias de Mn encontradas para Cambissolos catarinenses (395,9 $\left.\mathrm{mg} \mathrm{kg}^{-1}\right)$ foram semelhantes as encontradas para Cambissolos mineiros $\left(386,5 \mathrm{mg} \mathrm{kg}^{-1}\right.$ ) (CAIRES 2009). Já para os Argissolosnão houve semelhança, sendo constatados teores de $65,6 \mathrm{mg} \mathrm{kg}^{-1}$ de $\mathrm{Mn}$ nos solos de Santa Catarina e 248,7 $\mathrm{mg} \mathrm{kg}^{-1}$ para solos Minas Gerais. Os teores de Mn em solos de Pernambuco (BIONDI et al. 2011) e Rio Grande do Norte (COSTA 2013) também foram diferentes dos encontrados neste trabalho.

Essas variações entre os teores de Co e Mn encontrados pelos diferentes autores nos estudos com solos naturais do Brasil fortalece a afirmação de que é necessário determinar os teores naturais dos elementos para cada local, devido às diversidades geológicas, geomorfológicas e pedológicas do país.

Os teores de $\mathrm{Mn}$ e o Co no solo apresentaram correlação positiva (Tabela 6), o que demonstra elevada afinidade geoquímica entre ambos. Solos com menor teor de Mn apresentam maior mobilidade de Co, já que este possui afinidade com os óxidos de manganês, uma vez que é adsorvido na superfície destes (LANGE et al. 2014). LI et al. (2001) também observaram correlações altamente significativas entre cobalto e manganês em solos da Nova Zelândia, justificadas pela estreita relação geoquímica entre os elementos.

Tabela 6. Coeficientes de correlação linear de Pearson entre os teores de $\mathrm{Mn}$ e Co e os atributos do solo Table 6. Pearson's correlation coefficients between Mn and Co contents and their soil attributes.

\begin{tabular}{lcc}
\hline & Mn & Co \\
\hline Co & 0,88 & 1,00 \\
silte/argila & 0,42 & 0,47 \\
SB & 0,61 & 0,63 \\
V & 0,74 & 0,78 \\
argila & $-0,13$ & $-0,08$ \\
\hline
\end{tabular}

Não houve correlação significativa entre teor de argila e teores de Co e Mn. Já a relação silte/argila apresentou correlação significativa e positiva com os teores de $\mathrm{Mn}$ e Co no solo, ou seja, o grau de intemperismo e lixiviação dos solos está diretamente relacionado aos teores de Co e Mn. Esta correlação confirma o que foi discutido anteriormente, sendo que solos jovens como os Chernossolos possuem teores de Co e Mn superiores aos de solos intemperizados como os Latossolos, mesmo que ambos sejam derivados do mesmo material de origem.

A forte correlação entre a soma e saturação de bases e os teores de Co e $\mathrm{Mn}$ no solo também reafirmam a influência do grau de intemperismo e lixiviação dos solos. Sendo assim, percebeu-se que em geral, solos mais jovens, com menor grau de intemperização e lixiviação, apresentaram maiores teores de Co e $\mathrm{Mn}$.

\section{CONCLUSÃO}

Em geral, os maiores teores de cobalto e manganês foram observados em solos originados de rochas magmáticas básicas, em especial máficas e com menor grau de intemperismo e lixiviação.

Relação silte/argila, soma de bases e saturação de bases se correlacionaram positivamente com os elementos estudados.

Teores naturais de cobalto e manganês em solos catarinenses, diferiram dos encontrados por outros autores para diferentes estados brasileiros, confirmando a necessidade de obtenção de valores de referência para cada estado.

\section{REFERÊNCIAS}

ALMEIDA JA et al. 2009. Genesis of the sombric horizon in Ultisols (red argisols) in southern Santa Catarina, Brazil. Revista Brasileira de Ciência do Solo 33: 405-416.

ALMEIDA JA et al. 2003. Cor de solo, formas de fósforo e adsorção de fosfato em latossolos desenvolvidos de basalto do extremo-sul do Brasil. Revista Brasileira de Ciência do Solo 27: 985-1002.

APHA. 2012. Standard methods for the examination of water and waste, Washington, DC, New York: American Public 
Health Association.

ATSDR. 2012. Agency for Toxic Substances and Disease Registry. Toxicological profile for manganese. Atlanta, GA: U.S. Department of Health and Human Services, Public Health Service.

ATSDR. 2015. Agency for Toxic Substances and Disease Registry. The priority list of hazardous substances that will be the candidates for toxicological profiles. Atlanta, GA: U.S. Department of Health and Human Services, Public Health Service.

BARCELOUX DG. 1999. Cobalt. Journal of Toxicology. Clinical Toxicology. 37: 201-216.

BIONDI CM et al. 2011. Teores de Fe, Mn, Zn, Cu, Ni e Co em solos de referência de Pernambuco. Revista Brasileira de Ciência do Solo 35: 1057-1066.

BRINGHENTI I et al. 2012. Mineralogia e gênese de argissolos das Serras do Tabuleiro/ltajaí, Estado de Santa Catarina. Revista Brasileira de Ciência do Solo 36: 1057-1071.

CAIRES SM de. 2009. Determinação dos teores naturais de metais pesados em solos do estado de Minas Gerais como subsídio ao estabelecimento de valores de referência de qualidade. Tese (Doutorado em Solos e Nutrição de Plantas). Viçosa: UFV. 321p.

CONAMA. 2009. Conselho Nacional do Meio Ambiente. Ministério do Meio Ambiente. Resolução 420, de 28 de dezembro de 2009.

CORRÊA J. 2003. Mineralogia e gênese das principais classes de solos de encostas basálticas do Estado de Santa Catarina. Dissertação (Mestrado em Ciência do Solo). Lages: UDESC. 92p.

COSTA A da et al. 2013. Pedotransfer functions to estimate retention and availability of water in soils of the state of Santa Catarina, Brazil. Revista Brasileira de Ciência do Solo 37: 889-910.

COSTA WPLB da. 2013. Metais pesados em solos do Rio Grande do Norte: Valores de referência de qualidade e relações geopedológicas. Tese (Doutorado em Agronomia). Recife: UFRPE.123p.

ERNANI PR. 2008. Química do solo e disponibilidade de nutrientes. Lages: O autor. 230p.

FADIGAS FS et al. 2006. Proposição de valores de referência para a concentração natural de metais pesados em solos brasileiros. Revista Brasileira de Engenharia Agrícola e Ambiental 10: 699-705.

FERREIRA ERNC. 2013. Química e mineralogia de solos desenvolvidos de rochas alcalinas e ultrabásicas do domo de Lages. Tese (Doutorado em Manejo do Solo). Lages: UDESC. 161p.

FORBES EA et al. 1976. The specific adsorption of divalent $\mathrm{Cd}, \mathrm{Co}, \mathrm{Cu}, \mathrm{Pb}$, and $\mathrm{Zn}$ on goethite. European Journal of Soil Science 27: 154-166.

HE ZL et al. 2005. Trace elements in agroecosystems and impacts on the environment. Journal of Trace Elements in Medicine and Biology 19: 125-140.

HOWE PD et al. 2004. Manganese and its compounds: environmental aspects. Geneva: World Health Organization. $63 p$.

HUGEN C. 2010. Valores de referência para teores de $\mathrm{Cr}, \mathrm{Cu}, \mathrm{Ni}, \mathrm{Pb}$ e $\mathrm{Zn}$ em solos do estado de Santa Catarina. Dissertação (Mestrado em Manejo do Solo). Lages: UDESC. 70p.

HUGEN C et al. 2013. Teores de $\mathrm{Cu}$ e $\mathrm{Zn}$ em perfis de solos de diferentes litologias em Santa Catarina. Revista Brasileira de Engenharia Agrícola e Ambiental 17: 622-628.

KABATA-PENDIAS A \& MUKHERJEE AB. 2007. Trace Elements from Soil to Human. Berlin: Springer-Verlag. 550p.

LANGE B et al. 2014. Prediction of the edaphic factors influence upon the copper and cobalt accumulation in two metallophytes using copper and cobalt speciation in soils. Plant and Soil 379: 275-287.

LI Z et al. 2001. Cobalt and manganese relationships in New Zealand soils. New Zealand Journal of Agricultural Research 44: 191-200.

LISON D. 2007. Cobalt. In: NORDBERG GF et al. (Eds.). Handbook on the Toxicology of Metals. San Diego: Elsevier. p. 521-528.

LUNARDI NETO A \& ALMEIDA JA 2013. Mineralogia das frações silte e argila em Argissolos com horizontes subsuperficiais escurecidos em Santa Catarina. Revista de Ciências Agroveterinárias 12: 282-293.

NORVELL WA. 1988. Inorganic Reactions of Manganese in Soils. In: GRAHAM RD et al. (Eds.). Manganese in Soils and Plants. Dordrecht: Kluwer Academic Publishers. p. 37-58.

PAES SOBRINHO JB et al. 2009. Mineralogia, propriedades químicas e classificação de solos das Serras do Leste Catarinense. Revista de Ciências Agroveterinárias 8: 9-24.

PLUMLEE GS \& ZIEGLER TL. 2003. The medical geochemistry of dusts, soils, and other earth materials. Treatise On Geochemistry 9: 263-310.

PRESTON W et al. 2014. Valores de referência de qualidade para metais pesados em solos do Rio Grande do Norte. Revista Brasileira de Ciência do Solo 38: 1028-1037.

R CORE TEAM. 2016. R: A Language and Environment for Statistical Computing. R Foundation for Statistical Computing, Vienna, Austria.

REIMANN C \& CARITAT P. 1998. Chemical elements in the environment: fact sheets for the geochemist and environmental scientist. Berlin: Springer-Verlag. 398p.

SANTOS SN \& ALLEONI LRF. 2013. Reference values for heavy metals in soils of the Brazilian agricultural frontier in Southwestern Amazônia. Environmental Monitoring and Assessment 185: 5737-5748.

SOUZA LC. 2015. Teores naturais de arsênio, bário, cádmio e níquel para solos do estado de Santa Catarina. Tese (Doutorado em Ciência do Solo). Lages: UDESC. 147p. 
TESKE R et al. 2013. Caracterização química, física e morfológica de solos derivados de rochas efusivas no Planalto Sul de Santa Catarina, Brasil. Revista de Ciências Agroveterinárias 12: 175-186.

USEPA. 1996. "Method 3050B: Acid Digestion of Sediments, Sludges, and Soils," Revision 2. Washington, DC. 12p.

XAVIER BT de L. 2013. Mineralogia e teores naturais de metais pesados em solos da bacia sedimentar amazônica. Tese (Doutorado em Solos e Nutrição de Plantas). Viçosa: UFV. 110p. 